\title{
Determinants of Individuals' Willingness to use EconomicInstruments for Solid Waste Management in Dar es Salaam:The case of Mwananyamala and Mikocheni wards
}

\author{
Emmanuel N Kazuva* \\ Open university of Tanzania, Africa
}

Submission: August 19, 2017; Published: September 06, 2017

*Corresponding author: Emmanuel N Kazuva, Open university of Tanzania, PO Box 23409, Dar es Salaam, Africa, Tel: 255 715- 282 091;

Email: ekazuvae@gmail.com

\begin{abstract}
The existing systems of solid waste management (SWM) in the city of Dar es Salaam suffer from the lack of a good plan and appropriate approach for their sustainability. This empirical study explores the problem of solid waste (SW) in Kinondoni Municipality, Dar es Salaam, Tanzania. It highlights the impacts of applying economic instruments (EIs) on SWM with much emphasis on the relationship between socioeconomic characteristics of the communities and their willingness to use such instruments or pay for the service. The study involved 217 households whereby, questionnaires, key informants' interview, focus group discussion and observation were used for data collection. Solid waste problem was found to be at the climax and alarming stage, especially in unplanned settlements due to the complications related to such settlements. Despite that only few EIs are used for the purpose, inappropriately; majority of respondents (85.3\%) indicate their willingness to use and pay for the service and acknowledge on the available opportunities for sustainably use of economic instruments.
\end{abstract}

Keywords: Solid waste; Economic instruments; Command; Control regulations

Abbreviations: SWM: Solid Waste Management; EIs: Economic Instruments; CACs: Command and Control; ISWM: Integrated Sustainable Waste Management; GNP: Gross National Product; MSW: Municipal Solid Waste; OECD: Economic Co-operation and Development; ICT: Information and Communications Technology; UNED: Environment and Development; SMEs: Sized Enterprises; CACs: Control Regulations; DCC: City Council

\section{Introduction}

The existing solid waste management (SWM) systems in many cities particularly of the developing countries suffer from the lack of appropriate plans and approaches for implementation. For sustainable solid waste and general environmental management, application of both Economic Instruments (EIs) and Command and Control (CACs) regulations are inevitable Kaseva 2013. In Tanzania, CACs regulations have been used with little or without any EIs; resulting into unsustainable SWM. The threat of solid waste to the health and general livelihood has been recognised in both Abidjan, 1984 and Nairobi, 2010 conventions which indicated that, the haphazardly dumped solid waste (SW) leads to the degradation of both inland and coastal habitats. The conventions propose various strategies and measures to combat this problem. The proposed measures and strategies include, inter alia, ensuring that SW are not dumped on or around these sensitive habitats and installing adequate SW disposal facilities. These are to be facilitated by introducing different economic instruments (EIs) that encourage the 3R (recovery, reuse and recycle); the way for sustainable SWM. However, in all these strategies there have been a number of challenges limiting their implementation. These include the fact that, many urban areas lack adequate waste collection and disposal facilities Omololu and Lawal [1]. As the results, quite often waste are dumped in open spaces, along and across streets, in drains, water bodies and such similar places; causing mortality to marine biodiversity, poor aesthetic on recreation and tourism potential areas and hazardous environments for navigation hence direct and/ or indirectly health problems in different ways Ntakamulenga [2].

Together with other factors behind the rapid increase of waste generation, the impact of urbanization can't be ignored. In Dar es Salaam, the main commercial city of the country, urbanization stands at $4.9 \%$ and more than $70 \%$ of its dwellers live in unplanned and un-serviced settlements Robert [3]. These areas are characterized by excess poor SWM. With a population 
of more than 4.5 million people, solid waste generation is amounting to $3100 t /$ day while only1200t/day (39\%) is properly disposed Buenrostro [4]. With such rapid growing population and urbanization, there is undoubtedly increased rate of solidwaste generation too.

The city council has been coming up with a number of solutions including application of economic instruments (EIs) to address waste management challenges in the city. The general questions that one may ask here are; to what extent has such EIs application helped to manage solid waste in the City? Are these instruments accepted and is the community willing to pay for the services? This study provides empirical evidence on this area of inquiry.

\section{Objectives}

Three specific areas of inquiry were the core objectives of the study:

a) Investigating the kind of solid waste generated at households and methods used for managing,

b) Identify and analyzing the efficacy of economic instruments applied in managing solid waste; and

c) Analyzing the determining factors for individuals' willingness to use economic instruments in relation to their social economic characteristics.

The study is critical to urban area of the country scrutinizing the city of Dar es Salaam. It explores the extent at which economic instruments have been employed and the challenges encountered. It seeks to contribute to the body of knowledge by exploring the un-grabbed opportunity in using EIs and thus informing the policy makers on how best economic instruments should be applied for effective management of solid waste and encourage private involvement as an employment opportunity.

\section{Literature Review}

\section{The concept of solid waste}

The term waste is a very subjective term which involve something that one may see it as waste whilst another might see it as a resource Williams [5]. It therefore has different meaning to different people in different perspectives. In general, it refers to "unwanted" for the one who discards it and a material or product that does not have value anymore to the first consumer/user and is therefore thrown away. In integrated sustainable waste management (ISWM), waste is regarded as both negative and useful materials. It is negative when distort the environment in any manner whatever and useful materiel when treated in a way that ends in providing a potential source of income. It can be the only free resource available to the poor people, or urban dwellers that cannot cut and use wood or any other common resources Angelo [6]. The value of waste in many low-and middle-income people in the south is confirmed by the large informal sector that depends on waste collection and recovery activities. There is also formal sector which use some byproducts to produce new valuable products. Example of this includes sugar cane waste to paper production factories. Unfortunately, not all wastes can be regarded as resource. Some of these byproducts contain hazardous and toxic materials which cannot be safely recycled or reused USEPA [7].

\section{Solid Waste general Situation}

It is clear that in most cities of the world; SW quantities are increasing rapidly than collection capacities UN-Babitat, 2010. This is happening because of the major number of reasons, including:

a) The rapid increase in number of people living and working in cities

b) The increase in varieties and complexity of waste substances

c) The increasing amount of generated waste from business, and

d) The increase in wealth which raises the amount of waste generated per capita.

As the results, SW has become one of the most important environmental concerns facing humankind in modern times. The problem is even serious to third world countries which lack important facilities for waste monitoring and management. Its production and disposal is a growing problem for both developed and developing countries. As highlighted by Cooper, 2001. Almost in every country waste production is said to increases nearly the same as the growth of its GNP (gross national product). Most local governments and urban development agencies have from time to time identified SW as a major problem that has reached proportions requiring drastic corrective measures.

Estimating the global waste generation figures is somewhat difficult, given the unreliability of data, especial for low and middle income countries. According to UN Habitat, 2010, municipal solid waste generation worldwide in 2009 was estimated to be 2.1 billion tones, with a $38 \%$ increasing forecast by 2012 . Since global human population is hastily growing the waste generation is expected to increase in the near future. The great concern is on the mismatch between the population growth and the capacity of the world system to absorb the changes. As stated by Kibert 2005, "rapid growth of population and the increase in consumption has resulted into mismatch between the capacity of human activities and the natural systems which result into miss function of these natural systems". If not checked therefore, SW will be a calamity in most developing countries in few years to come.

As postulated by Robert [3], the rate of SW generation in Tanzania especially in Dar es Salaam is of particular concern considering the low capacity of local authorities (LAs) in terms of resources required for waste collection and management. In Kinondoni municipal, while the amount of SW generated 
per day was estimated to be more than 2000 tonnes in 2014, the municipal was capable to collect only 811 tones daily DLA 2014. Since then the trend has been proportionally growing with a slight increase in collection rate. In general, three key trends with respect to solid waste management have been globally observed: First is an increase in volume of waste generated by urban residents, second is the change in quality and/ or composition of the waste generated and the third is disposal methods of waste collected GDRC, 2008. The disposal of waste is increasingly becoming difficult, with the diminishing numbers of suitable sites for landfill disposal. However, landfill is still the most common route of waste disposal in the country Philips [8].

\section{Classification of Solid Waste}

Municipal Solid Waste: Municipal solid waste (MSW) refers to the waste materials that are discarded in the urban areas of which municipalities are often held responsible for taking care of (collection, transportation and final disposal). Such waste includes household refuse, street sweeps, institutional waste, commercial waste as well as construction and demolition debris Medina 2002; Schubeler 1996. As in other types of waste, municipal solid waste, the amount of MSW generated has also been rapidly increasing while the collection capacities of the respective authorities are slowly changing. In about ten years ago, there were approximately 2.9 billion urban inhabitants who generated about $0.64 \mathrm{~kg}$ of MSW per person per day $(0.68$ billion tonnes per year) Web group (2008). Today, the story has changed. The world urban population has increased to about 3.9 billion residents generating approximately $1.2 \mathrm{~kg}$ per person per day, (1.6 billion tonnes per year). By 2025 this will likely to increase to about 4.3 billion urban residents generating about $1.43 \mathrm{~kg}$ of MSW per person per day (2.2 billion tonnes per year). Unless properly managed, this will pose a serious environmental concern World Bank 2013 and UNES [9].

Industrial waste/ Trade Waste: These are all wastes arising from industrial operations and/ or derived from manufacturing processes Abduli [10]. It encompasses solids, liquids, gases and sludge's. They can be characterized according to whether they are hazardous or nonhazardous. Although the literature suggests that majority of the industrial waste in developing countries is of non-hazardous nature, hazardous waste still represents serious environmental and health threats to these countries Polrasert 1996. More often waste in developing countries is untreated and disposed of the unsafe manner. This include illegal dumping, open dumps, sea, lakes, and in rivers.

Hospital Waste/ Biomedical Solid Waste: Medical waste is all waste materials generated at health care facilities, like hospitals, physicians' offices, dental practices, blood banks, and veterinary hospitals/clinics, as well as medical laboratories and research facilities EPA [11]. It is the second most hazardous waste after radioactive which is the most dangerous waste. The term "hazardous waste" means SW or a combination of solid with other forms of wastes, which significantly may cause or contribute to an increase in mortality or a serious reversible or irreversible illness. These wastes if improperly managed especially during storage, treatment, transportation, and final disposal are said to pose serious problems to human health and potential hazards to the environment EPA, 2006. In Tanzania, this type of waste was ranked the first in terms of hazardous contained and forth in terms of quantity produced Kazuva 2015.

Electronic Waste (e-waste): E-waste is a term used to cover almost all types of electrical and electronic equipment that enter the waste stream. Although e-waste is a general term, it can be considered to cover TV sets, mobile phones, computers, and white goods like fridges, dryers, washing machines etc. It also includes home entertainment and stereo systems, toys, kettles and almost any household or business item with electrical components or battery supply. This waste is the most rapidly growing segment of the municipal waste stream Mesker 2014.

E-waste has been noted to grow exponentially simply because the markets to which these digital products are produced have been rapidly growing as well. For example, as noted by the organization for economic co-operation and development (OECD) between 2000 and 2005, there was a notable growth in $22 \%$ of information and communications technology (ICT) in China. In 2006, China was the 6th largest ICT market, after the US, Japan, UK, France and Germany. This is an outstanding when one considers that just ten years ago, less than $1 \%$ of China's population owned a computer Mesker, 2014.

\section{SW- Management strategies in Dar es Salaam}

Management of solid waste in Dar es Salaam, the commercial capital city of the country, is principally the direct responsibility of Local Authorities (governments). This is through Urban Authority Act of 1982, Section 55 (g), which imposes to them the mandate to remove refuse and filth from any "public or private place" and maintain refuse containers in a good condition for temporary collection and deposit URT, 2004. However, for many years now, the City Council and its three Municipalities Kinondoni, Temeke and Ilala have been confronted by growing volume and volumes of SW and the inadequate provisions for its removal and the final disposal Lyeme [12].

Before privatization, the City Council (DCC) was the only authority in Dar es Salaam responsible for provision of public services, including primary waste collection, streets' sweeping, temporary storage, transportation to disposing sites, management of those sites, and sometimes recycles the waste. To effectively perform these activities, the DCC was essentially supposed to have a robust budget for funding SWM activities, adequate personnel and equipments to execute these activities. The city residents, developers, business operators, as waste generators relied on the DCC as the sole SWM service provider in return to taxes they paid.

While operating under such situation of the conventional approaches, the DCC proved failure in providing efficient and 
reliable services to the rapidly growing population of the city Halla and Majani [13]. It was capable of collecting only between 30 and 60 tonnes equivalent to $2 \%$ to $4 \%$ of the then total waste generated per day in the city UCLAS, 2003. Low income neighborhoods and cites locations like Central Business Districts (CBD) in Dar es Salaam were severely affected by flooding as the results of blockages of drain and air pollution from decay and rotting of haphazardly dumped or uncollected heaps of wastes. The insanitary and health threatening situation in the CBD led together with other impacts, to a drop in the number of local business customers, expected number of tourists visits and the international businessmen Halla and Majani [13] ; UCLAS 2003.

The franchise type of privatization was adopted according to the experiences gained in the past in the City. Under this arrangement a private contractor is given a finite-term zonal monopoly for delivery of SWM service, after a competitive pre-qualification process. The private contractor recovers its cost through Direct User Charge (DUC) levied on the service beneficiaries according to rates set by the City Council and the three Municipalities URT, 2004. The system of collecting waste is mainly door-to-door collection in high income areas using open trucks, farm tractors, and sometimes small pickups. For low-income areas, where most settlements are not planned and underserviced, the main collection system used is communal collection. In this regard, households dispose waste in enclosures located along roadside. Door-to-door collection is partly practiced whereby push/ handcarts are used to dispose the waste either at the contractor's or municipal collection points Kaseva 2013.

\section{Challenges on Solid Waste management}

Municipal solid waste collection schemes in cities of the developing world usually serve only a limited part of the urban population. Many people who remain without waste collection services are generally the low income population living in peri-urban areas Lyeme [12]. One of the main reasons is lack of financial resource to cope with the increasing amount of generated waste from the rapidly grow cities. Often inadequate fees charged results into limited funds from a central municipal budget cannot finance adequate service. However, not only financial problem affects availability or sustainability of a waste collection services. Other factors dictating operational inefficiencies of SW include inefficient institutional structures and organizational procedures, inappropriate technologies as well as deficient in management capacity from the institutions involved Zurbrugg [14]. So in general, the typical challenges that are facing management of municipal solid waste in developing countries can be summarized as;

a) Inadequate services coverage and operational inefficiencies of services

b) Inadequate management of hazardous and healthcare waste c) Non or limited utilization of recycling activities and

d) Inadequate landfill disposal

There are some other challenges associated to technical system and "conventional" collection approaches which in their holistic affect SWM in the city. These include the fact that the applicability of these systems and approached which have designed and used in the industrialized countries are limited in the developing countries in terms of infrastructure and the general environment. There is also a fast growing interest of involving private companies in SWM. This has nothing bad with SWM but when it comes that it is influenced by the pressure from national government and international agencies; they all stand as challenges toward sustainable SWM Jim, 2008.

\section{Economic Instruments (EIs)}

Economic instruments are fiscal and other economic incentives and disincentives to take in environmental costs and benefits into the budgets of waste producers (i.e. households and enterprises). The main objective in this is to encourage environmentally sound and efficient production and use through full-cost pricing Jürg, 2011. EIs have drawn increasing attention in recent years as an important tool for implementing and reinforcing environmental legislation framework while simultaneously contributing to sustainable development. Specifically, economic instruments for solid waste management promise both lessened magnitude of SWM production and improve delivering of SW collection and disposal services. In 1992 the UN conference on Environment and Development (UNED) endorsed the use of EIs as a means to attain sustainable environmental improvement UNEP [15].

Economic instruments help to deliver the objectives of the waste management strategies by using the price incentive mechanism. This process provides not only short term incentive to reduce pollution, but they provide permanent incentives for investment, add innovation in processes that result in less pollution, and encourage the use of cleaner products Gervais [16]. EIs may be useful tools in reducing the amount of SW being disposed. With well monitored legislation, EIs can provide financial incentives for businesses to reduce, re-use and recycle waste (3R). A range of Economic Instruments, including depositrefund systems, raw material and product charges, liability payments, emission taxes performance bond, non-compliance fees, waste collection and disposal charges, taxes and subsidies, etc. are available for the use of influencing behaviour towards sustainable waste management Powell and Craighil [17], Klarer [18]. Some of the economic instruments include the following:-

Direct Charge: This is the practice of charging expenditures directly Martin, 2004. It is an instrument to encourage public participation in recycling. Households and business are charged a fee based on the volume or weight of waste produced and/or the frequency at which waste is collected Williams [5]. Variety or methods such as the purchase of special refuse bags, the cost 
of which includes the waste collection and disposal costs are available for this scheme Powell and Craignhill [17]. Another example includes pay-by-weight using a chapped bin Martin, 2004. The tool has been used in most industrial countries like Colombia, Canada and the US. It has also been used in developing countries like South Africa, Ghana, and Tanzania Godfrey and Nahman [18], Klarer [19]. In South Africa the instrument has largely helped to manage SW by introducing normal trade waste collection, usually per bin bases Godfrey and Nahman [18]. However, the practice has some disadvantage like the possibility of increasing illegal dumping of waste Williams 2003, an increase in waste burning and the cost of providing education which is needed for the tool to work effectively Powell and Craighill [17].

Deposit-refund system: This is a scheme which involves the combination of a tax and a subsidy that may be imposed by law or be market-generated Powell and Craighill [17]. The consumers pay either a formal deposit or pay a higher product price, which is returned to them when they return the packaging to the seller Turner [20]. The tool has evidently been used in both developing and developed countries but generally limited in developing countries to some ways Panayotue, 1994. One of the strength of the scheme is that, the packaging can be refilled or recycled, thus reducing the amount of waste produced to the environment.

In addition, it helps to reduce the costs of waste collection and disposal, and the energy and resources required for container production Powell and Craighill [19]. However, the scheme can cause an increase in storage and handling costs resulting into inconvenience to the household Powell and Craighill [19]. An increase in storage and handling costs, combined with the need for extra storage space, could result in such a scheme being unpractical for small and medium sized enterprises (SMEs). Such a scheme could be successful in decreasing the amount of SW disposed, provided that the businesses have enough storage space, and monetary rewards are combined with convenience, for example, multi bottle collection in the United Kingdom Powell and Craighill [19].

Landfill Tax: A landfill tax or levy is a form of tax that is applied in some countries to increase the landfill cost. The tax is typically levied in units of currency per unit of weight or volume Fischer 2012. It is added to the overall landfill cost and forms a proportion of the gate fee. The tax applies to all waste disposedoff by way of landfill to the licensed landfill site unless the kind of waste is specifically exempt. As pinpointed by Cointreau [21] the tools is highly applied in many developed countries like in the New Zealand, UK and USA; but are very limited in developing countries.

Application of landfill tax has a number of advantages including the fact that, it internalizes some of the external costs of landfill, raises revenue for inspection programs or long- term mitigation measures of environmental impacts related to disposal and reduces the amount of waste going to landfill by encouraging waste minimization and /or more recycling. However, despite such applicability, landfill tax requires modern technology to operate effectively. It may also cause a number of problems like damage (disruption) of infrastructure like the access roads by heavy vehicles and pollution of the local environment. Environmental pollution includes contamination of groundwater or aquifers by leakage or sinkholes Rasht [22].

Recycling Credits: This instrument encourages the recycling of household waste by applying the payment to those who divert materials from final disposal for recycling Arthur and Eduljee [23]. The principle behind recycling credit scheme is that collection and sorting of waste receive the saving that the disposal authorities make on waste diverted from landfill Töpfer 2005. The UK environmental protection Act 1990 obliges the waste disposal authorities to pay the waste collection authorities recycling credits for all the waste that the collection authority recycles.

In addition, the waste disposal authority pays anyone who recycles waste, for example, community group and private organization DEFRA [24]. An advantage of this policy is that it provides effective solutions for delivering recycling services and reduces the total volume of municipal waste disposed at landfill sites. In other words, the scheme ensures that the desired recycling rates is met and hence realizes and promote the principles of waste hierarchy.

Generally, when properly used, EIs introduce more flexibility, efficiency and cost effectiveness in SWM. They are likely to stimulate development of pollution control technologies and expertise in the private sectors. If well monitored, they provide a particular government with a reliable source of revenue which supports waste management programmes. IDB 2003 specifying the potential found when using EIs. The instruments allow easy separation of different forms of waste and ought to reducing the proportion of hazardous waste generated thus minimizing the adverse environmental impacts related to waste collection, transportation and treatment and disposal system/s. They also change behavior of the user and thus reduce the volume of waste generated. EIs generate sufficient revenues to cover costs, and encouraging 3Rs, i.e. recovery, reuse and recycling of wastes. In choosing reasonable EIs to the local environment a number of evaluation criteria are recommended to be considered. These include cost-effectiveness of the instrument, environmental effectiveness, revenue usefulness, ease for implementation administrative cost-effectiveness. Others include the capacity of the instrument to address a wide range of waste type in a given short-term/period of time and finally to consider the instrument that provide opportunity for economic development by maintains trade competitiveness and encourages industrial development and employment generation. 


\section{Community awareness, attitude and willingness to pay for Solid waste management}

Awareness means exposure that individual has on a given idea. A study conducted by Supe (1990) indicates that awareness exposes individuals to an idea but may lack detailed information on it. For instance, the community may know the name of an activity but may not know the details. Awareness makes one develop interest that is he/she becomes motivated to find more information about the new idea. Studies by Taneja (2006) suggest that lack of awareness is one of the barriers to community participation and motivation toward accepting the program. Any development program could be effective only when people are aware about it and the benefits that will accrue to them as a result of implementing it.

It is awareness that can change attitudes and affect the people's willingness to cooperate, and adequately participate in all the proceedings. General environmental awareness and information on health risks due to ineffective SWM practices are important factors which need to be continuously communicated to all sectors of the communities. In SWM, community participation can be by carrying waste to a shared container, by segregating waste to assist recycling activities, or by paying for waste management services. Public awareness and community participation would assist in obtaining guidance in carrying out strategic planning of SWM and to enhance appropriate levels of community participation and a two-way communication in planning and implementing of integrated SWM services World Bank [25].

Example of a continuous education and awareness campaigns include the regular "Green and Clean" campaigns to promote environmental awareness by the Metro Manila Women Balikatan Movement and the Green Forum in Manila UNEP [17]. Other include the Environmental Pioneer Brigade Programme in Sri Lanka where children are made aware of environmental problems and how to manage and/or be preventative of them. Generally, community education plays a big role in developing interest and participation in SWM. It buildup the knowledge, values, skills, experiences and determination of human capacity needed to work on solving waste management issues at individual and community level Syagga 1992.

\section{Material and Methods}

This study employs both qualitative and quantitative research techniques which made possible the collection of numerical and non-numerical data from the field Cresswell 2013; Johnson and Christensen 2012. Primary data required for the study have been collected from 217 households of Mwananyamala and Mikocheni wards through the guided questionnaires, focus group discussion and direct observation. Secondary data were gathered through interview and documentary review from key informants like NEMC, VPO, KMC and others with virtual knowledge on issues related to subject matter of the study.

\section{Description of study area and selection criteria}

The study was conducted at Mwananyamala and Mikocheni wards, both in Kinondoni Municipality. This Municipal is one of the three municipals of Dar es Salaam region, other being Temeke and Ilala. Kinondoni is the most populated amongst the districts, with half of the city's population residing within it KMC [26]. It is also home to many of the high-income suburbs like Masaki, Oysterbay, Ada Estate and Mikocheni. The geographical coordinates of the district is $6047^{\prime} 0^{\prime \prime}$ South and 39 o $16^{\prime} 0^{\prime \prime}$ East (Figure 1). The municipal has 27 wards, from which, Mwananyamala and Mikocheni were selected for this study. The two wards differ in terms of economic levels of the people and the settlement patterns. The former is among the low-income neighborhoods, characterized by poor settlement planning, low quality housing and poor social services. The later comprised of suburbs and it is characterized by properly planned and serviced location with at least quality social services. It is the home of some major political figures, government officials and some merchants. In this regard, Mwananyamala ward representing low class and marginalized population while Mikocheni was selected to represent mid and high income dwellers with planned and serviced settlement (Figure 1).

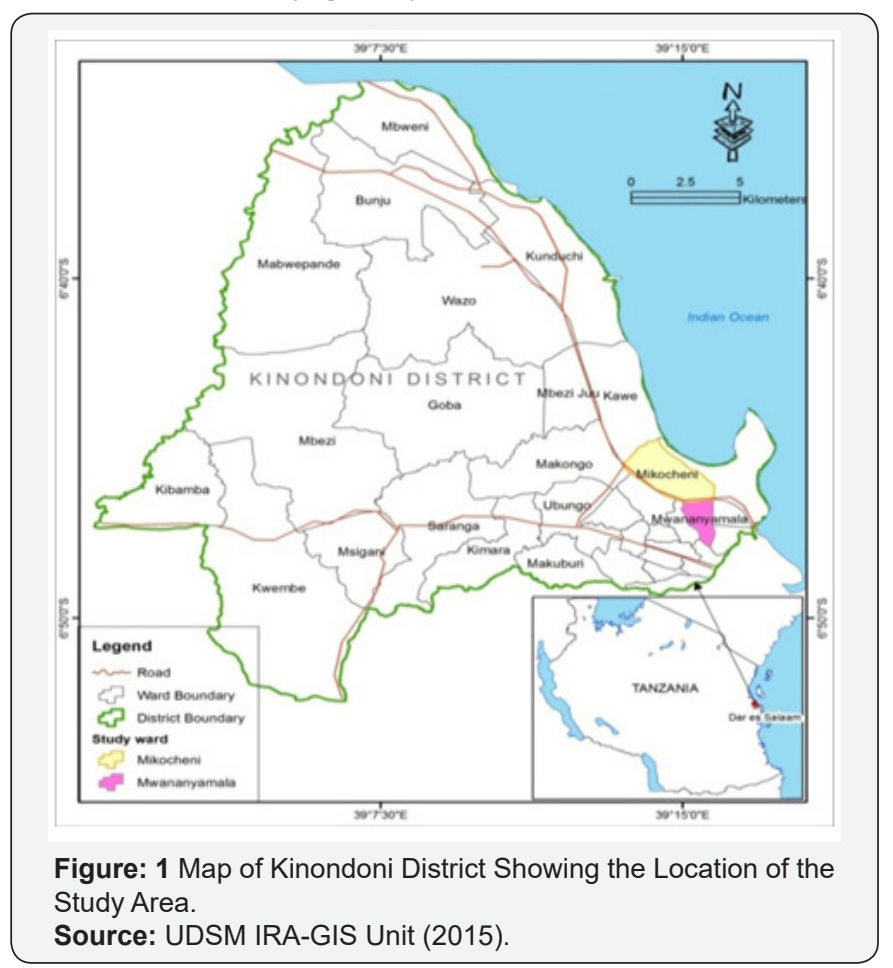

\section{Data analysis}

The SPSS software (Version-22) was used to analyze data where correlation and regression analysis (Chi-square test, ANOVA and some other related calculus) were used to make interpretation of data related to respondents attitude and WP for SWM possible. There were two holding uncertainties (hypothesis) that the researcher had before running a Chi-square test for accepting or rejection of either of the assumptions. These were Null and Alternative hypotheses which are states as:- 
a) Null hypothesis (Ho): There is no relationship between socio-economic characteristics of respondents and the willingness to pay for SW manage men (This was also termed as "Assumption Y" -in presentation section)

b) Alternative hypothesis (H1): There is relationship between socio- economic characteristics of respondents and the willingness to pay for SW management (This was also termed as "Assumption X"- in presentation section)

Then, chi-square test which is given by the following formula $x^{2}=\sum \frac{(0-E)^{2}}{E}$

was used to confiscate the holding uncertainty

Formula

Where

$\mathrm{O}=$ Observed frequency
To interpret data from Chi-Square test (See Table 1 II), two important conditions were used. The first is the use of $\mathrm{X} 2$ value and the critical value whereby the holding condition here is:-

\section{$\mathrm{E}=$ Expected frequency}

$\sum=$ Summation

$\mathrm{X}^{2}=$ Chi square value

If $\mathrm{df} \leq .05$, Null Hypothesis (Assumption "Y") will be Rejected; But if df > .05 Assumption Y (Null hypothesis) will be Retained.

The second condition is the use of degree of freedom (df) from computed data. The condition here is:-

Based on these conditions, the obtained data were interpreted and presented accordingly under presentation and discussion section.

If $X^{2}$ value is greater than the critical value, Null Hypothesis (Assumption "Y") will be rejected; and vice versa.

Table 1: Solid waste generated and collected in the study area

\begin{tabular}{|c|c|c|c|c|}
\hline Area & $\begin{array}{c}\text { Amount generated } \\
\text { (Tonnes/day) }\end{array}$ & $\begin{array}{c}\text { Amount collected } \\
\text { (Tonnes/day) }\end{array}$ & \% of total Collection & \% of uncollected waste \\
\hline Mwananyamala ward & 63 & 21 & $33 \%$ & $67 \%$ \\
\hline Mikocheni ward & 37 & 21 & $54 \%$ & $46 \%$ \\
\hline Kinondoni Municipality & 2026 & 811 & $40 \%$ & $60 \%$ \\
\hline
\end{tabular}

\section{Presentation and Discussion of Findings}

\section{The magnitude of SWM problem in the study area}

Solid waste management problem is one of the major socioeconomic and political agenda that face Kinondoni Municipality. It was found that, waste is haphazardly dumped in open spaces, along and across streets; in drains and such similar places in most parts of the study area especially at Mwananyamala ward (Figure 2). A number of efforts to get rid of the problem have been taken; though, they have never shown any promising future. About, 216 respondents (99.5\%) noted that SWM problem persists in their areas and that to $78 \%$, the problem is at the climax. Through direct observation, the researcher was able to observe the real existing waste situation in the study area (Figure 2).

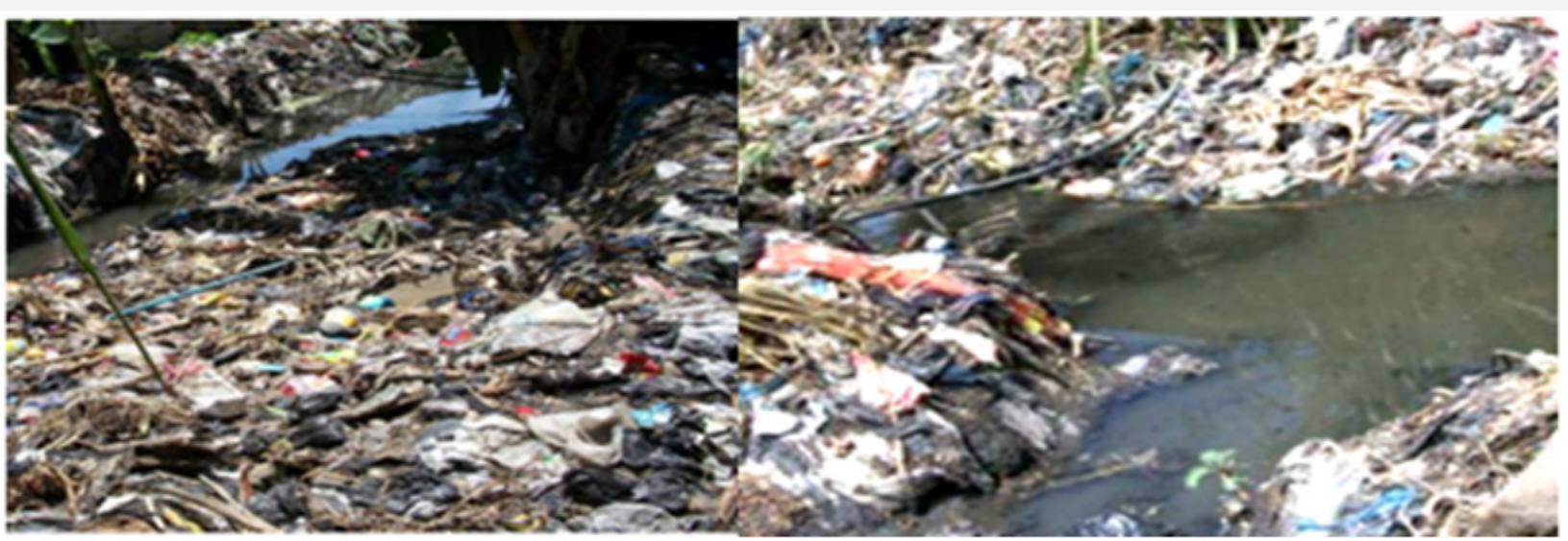

Figure 2: SW illegally dumped in drains at Bwawani; Mwanayamala ward.

Despite the fact that there are a number of regulations and bylaws governing SWM at the study area, it was observed that there are no workable measures that are taken against any violation. During FGD, residents highlighted the real problem of waste management in their respective areas. For example, concerning the matter of the situation and magnitude of solid waste, one respondent reported as follows: Dear researcher, you can just observe, this place has excessive waste accumulation. I am, personally, very much annoyed with the situation. Waste is haphazardly dumped everywhere in our place. It is surprising that even street leaders are also involved in this bad practice.

It seems no one is worried about the situation! Another respondent had the following to say: You can clearly see the 
condition of waste dumping in our area. Waste is simply dumped haphazardly around our houses. The problem is that, this place is not accessible. There are no passable street roads to let through the waste collecting trucks. Generally, Kinondoni produces more waste than any other municipality in Dar es Salaam. From the average of 3756 tonnes of waste generated per day in Dar es Salaam region for the year 2014, about 54\% (2028 tonnes) were from Kinondoni Municipality while only 19\% and 27\% were from Ilala and Temeke, respectively (DLA 2014). These findings are in consistent with the study by Solomon (2011) which showed that, of the total waste generated per day (3080 tonnes) in Dar es Salaam in 2010, only $42 \%$ were from Ilala and Temeke, the rest (58\%) were from Kinondoni Municipality. Since then, Kinondoni has been producing more waste compared to other Municipalities. The reason for this is that; Kinondoni is more populated than Ilala and Temeke. The study has found that, due to different challenges such as poor management strategies, infrastructure and facilities, on average only $40 \%$ of the total waste produced in Kinondoni municipality was collected while about $60 \%$ remain uncollected.

The situation was even worse in Mwananyamala ward. It was only $33 \%$ of the total waste produced were collected. The remaining $67 \%$ were illegally dumped or wait for unpredictable waste collectors. In general, the findings indicate a significant difference on waste situation among the two wards despite that the generation rate is almost the same. For instance, while only $33 \%$ of the total generated wastes per day are collected in Mwananyamala, about $54 \%$ of the generated waste was collected in Mikocheni, making it clean compared to Mwanayamala ward (Table 1). Interpretation that can be made here is that, waste generation rate in a given area is not necessarily be the determinant factor for the level of cleanness or filthiness of the particular area; other factors may dictate (Table 1).

Much of uncollected waste quantities were from unplanned areas of the wards especially Mwananyamala where squatter is a common feature of the settlement. Introducing waste collection schemes to such unplanned areas is a challenge given the lack of local awareness, institutional capacity, funds and the condition of area roads for collection vehicles to let through. Squatter settlement is a common feature in this ward. 4.2 presents an oblique view of part of Mwananyamala wards which shows how serious is the problem of an unplanned settlement. This makes it difficult for waste collection (Figure 3).

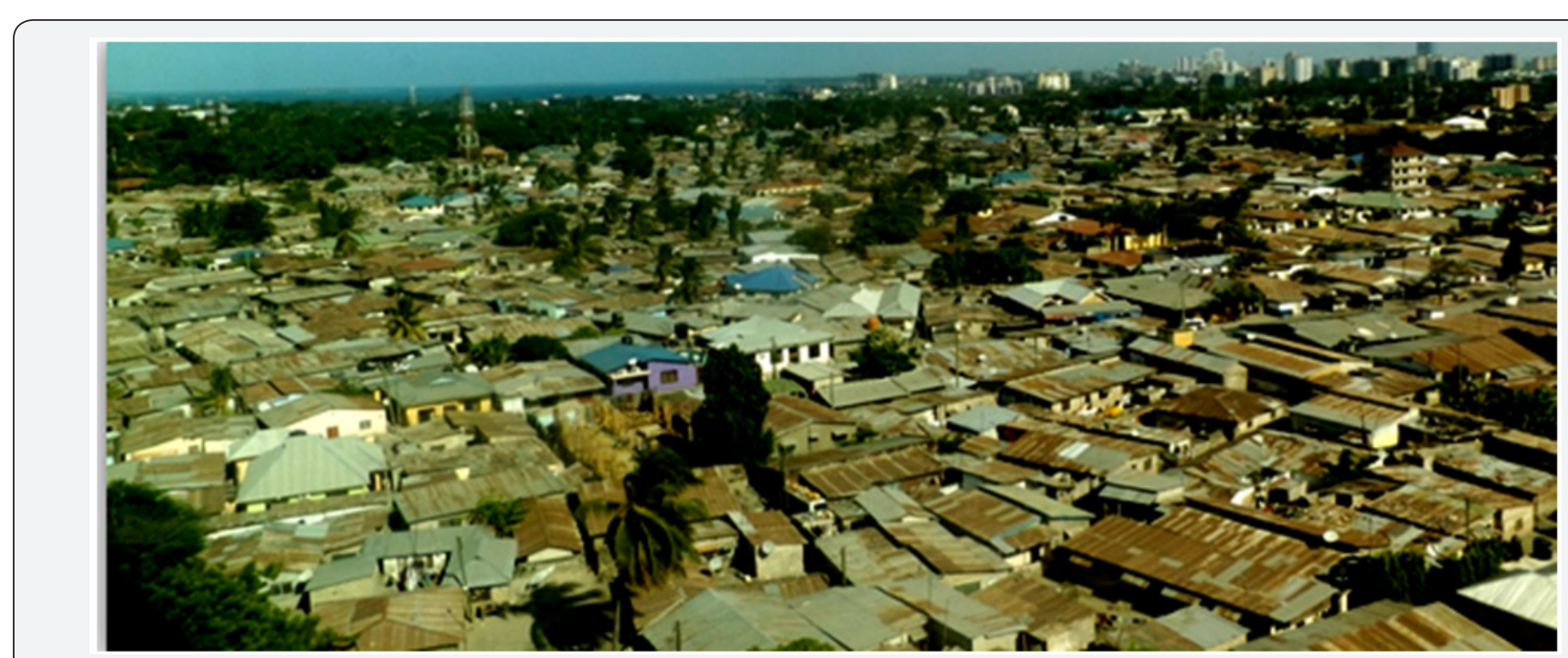

Figure 3: Unplanned settlements in Mwananyamala ward.

Source: Field data, (2016).

Type and at which capacity. The RbQ and $\mathrm{RbH}$ were two criteria used for ranking. The study findings confirm those of the previous study by Solomon (2011) which indicated that municipal SW was the leading type in terms of quantity produced. However, they differ from it in the rank of other types Table 2: The dominant types of Solid waste in the study area.

\begin{tabular}{|c|c|c|c|c|}
\hline Type of solid waste & $\begin{array}{c}\text { Percentage (\%) } \\
\text { composition of Quantity } \\
\text { in 100 tonnes }\end{array}$ & RbQ $^{\mathbf{1}}$ & $\begin{array}{c}\text { Percentage (\%) } \\
\text { composition of } \\
\text { hazardous in 100 tonnes }\end{array}$ & RbH $^{\mathbf{2}}$ \\
\hline Municipal solid waste & 42 & 1 & 16.7 & 3 \\
\hline Electronic solid waste & 19 & 2 & 10.3 & 4 \\
\hline Industrial solid waste & 17.5 & 3 & 32 & 2 \\
\hline
\end{tabular}

of waste in the list. From the estimated amount of SW produced in Mwananyamala and Mikocheni per day (100 tonnes); 42\% was municipal SW, 19\% - electronic waste and other types made $39 \%$ (Table 2). 
International Journal of Environmental Sciences \& Natural Resources

\begin{tabular}{|c|c|c|c|c|}
\hline Biomedical Solid waste & 15.5 & 4 & 34 & 1 \\
\hline Other & 6 & 5 & 7 & 5 \\
\hline Valid N (list-wise) & 100.0 & NA & 100.0 & NA \\
\hline
\end{tabular}

Source: Field data (2016)

${ }^{1}$ Ranking the type of SW based on Quantity produced

${ }^{2}$ Ranking the type of SW based on Hazardous contained

The main difference between the findings of this study and that of Solomon [27] was on electronic type of SW. In this study, electronic waste was found to be the second in terms of quantity produced since production has dramatically increased in the last five years and therefore exceeded industrial waste which the previous studies ranked it the second (ibid.). The possible reason for such tremendous increase of this type of waste is the importation of substandard electronic equipment like TV sets, mobile phones etc. to the domestic market which does not last longer and so haphazardly dumped. For hazard wastes, the findings of this study differ from Solomon [27] which indicated industrial waste to be the leading in terms of hazardous contained. For this study, information gathered from respondents and key informants indicate that, biochemical (hospital) waste is the leading type (Table 2).

\section{The dominant types of SW produced in the study area}

Understanding the types, nature and amount of SW produced in the study area was one of the core themes of this study. The knowledge enabled the researcher to assess the instrument/s used for waste collection and management and propose the appropriate approach/es for sustainability in SWM practices. From household questionnaire, respondents identified different types of SW that are dominantly produced in their areas. Through descriptive analysis, the collected data were analyzed and ranked to spot out the most produced Solid waste disposing technique and transportation methods:

Various techniques of disposing SW were reported to be used at different levels in the study area. Collection by hiring individual collectors was the leading technique, counting $40 \%$ of the total. These hired individual collect waste to the nearby collection point or into illegal disposing area. Other identified techniques include the use of skip-containers (24\%) and curbside collection (18\%). In all these techniques waste was collected at the door step of the households and delivered to the collection point (or transfer station) in the form of standby trailers or in open areas. There were notable differences in the technique used among the two wards. Individual collectors' technique (59\%) was mostly preferred by low-income class (Mwananyamala dwellers) compared to Mikocheni dwellers where it was only used by $9 \%$. The fact here was that, the technique demands less or no money at all; thus majority with low, medium and even some high income prefer it. Other techniques include landfill (with an overall of $12 \%$ ) and incineration which counts for $7 \%$ overall. These were rarely used and were mostly used by high income class.

The study also revealed several transportation methods that were used for transporting waste at the door step of the households, delivering to the collection point (transfer station) and finally to the dump sites. As for the case of disposing techniques, there was an apparent difference between Mwananyamala and Mikocheni on the rate at which a particular method is used. It was noted that, in most cases, the methods used in Mikocheni were rarely used in Mwananyamala and vice versa. For example, while $48 \%$ of the total respondents from Mwananyamala were using individual private collectors, half of the sampled population from Mikocheni (50\%) was using open trucks as their main waste transportation method. This means that, people from Mikocheni where most of its residents are of medium or high class (income) manage to use such methods that demand money. For Mwananyamala ward where most of its residents earn below USD 1 per day opt for such methods that demand less or no money at all.

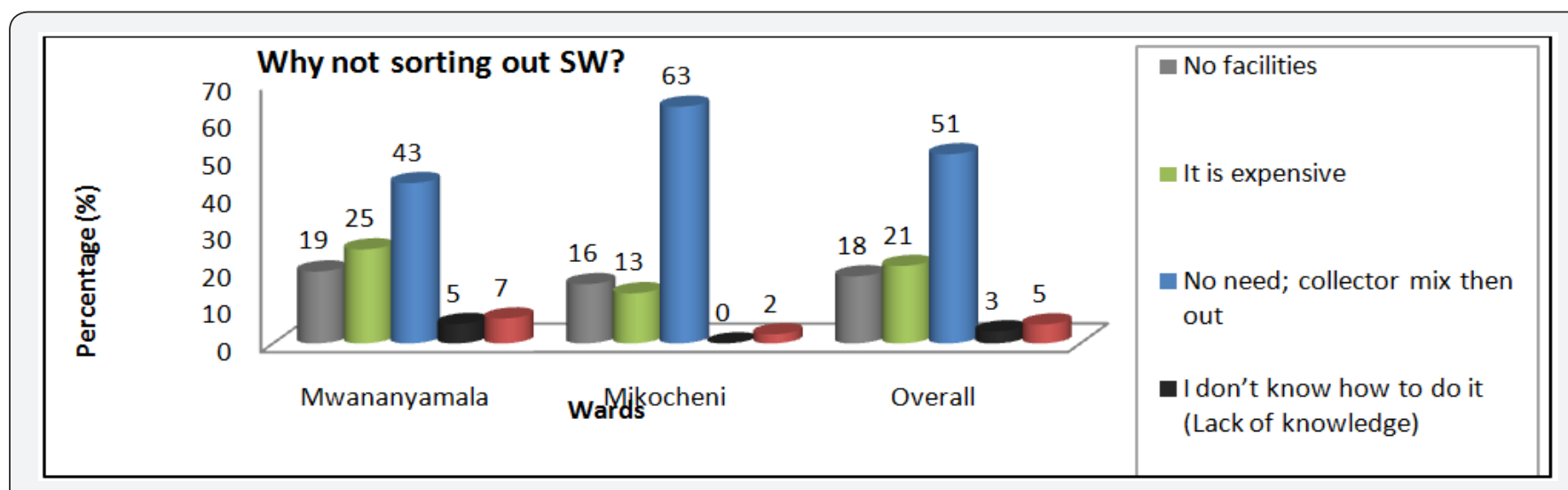

Figure 4: Factors for not sorting-out SW.

Source: Field data (2016). 
These include the use of pushcarts, burning and/or individual members of household carrying bags of waste to the collection point. These findings concur with literatures by Angelo [6] which postulate that, "individual's income determine the way of acting on the environment" There were two main reasons for Mwananyamala residents to opt for such least cost transportation methods. First, the methods are cheaper or do not require money and secondly, most parts of Mwananyamala area are unplanned settlements; therefore, introducing transportation methods like open trucks or farm tractors as for Mikocheni, could mean to collect only waste from households that are situated near the main roads, leaving out interior parts of the ward unsaved. (Figure 4) below is a comparison and overall methods used for transporting SW in the study area (Figure 4).

\section{Solid waste management strategies}

Sorting-out knowledge: Despite that majority of respondents at different levels understand and appreciate the needs for sorting out SW before collecting them for dumping; only $2.3 \%$ were manually practising the exercise. The remaining $97.7 \%$ do not sort out. Several factors were identified to be behind such failure. Slightly more than half (52\%) do not sort-out because waste collectors tend to mix and dump them together so they considered sorting as a wastage of time and resources. So sorting was not practically performed simply because individual households have no any use of the sorted waste. Other highlighted factors are shown in Figure 1 below.

It was noted that, those who claimed to have no knowledge on sorting waste; they were all from Mwananyamala ward. Although it is a small percentage in overall (3\%), the claim should not be ignored. This is because even those who claim to sort-out waste before collection (2.3\%), observation shows that, it was not the real sorting-out but just separation of liquid from solid domestic waste and it is done manually. After this separation, the remaining SW was collected together regardless of their differences. In this case, education on sorting out supported by economic incentive is very important. Figure 4.1 presents the factors for not sorting-out waste, indicating the different views from the given two wards and the overall sample.

Solid waste disposing technique and transportation methods: Various techniques of disposing SW were reported to be used at different levels in the study area. Collection by hiring individual collectors was the leading technique, counting $40 \%$ of the total. These hired individual collect waste to the nearby collection point or into illegal disposing area. Other identified techniques include the use of skip-containers (24\%) and curbside collection (18\%). In all these techniques waste was collected at the door step of the households and delivered to the collection point (or transfer station) in the form of standby trailers or in open areas. There were notable differences in the technique used among the two wards. Individual collectors' technique (59\%) was mostly preferred by low-income class (Mwananyamala dwellers) compared to Mikocheni dwellers where it was only used by $9 \%$. The fact here was that, the technique demands less or no money at all; thus majority with low, medium and even some high income prefer it. Other techniques include landfill (with an overall of 12\%) and incineration which counts for $7 \%$ overall. These were rarely used and were mostly used by high income class.

The study also revealed several transportation methods that were used for transporting waste at the door step of the households, delivering to the collection point (transfer station) and finally to the dump sites. As for the case of disposing techniques, there was an apparent difference between Mwananyamala and Mikocheni on the rate at which a particular method is used. It was noted that, in most cases, the methods used in Mikocheni were rarely used in Mwananyamala and vice versa. For example, while $48 \%$ of the total respondents from Mwananyamala were using individual private collectors, half of the sampled population from Mikocheni (50\%) was using open trucks as their main waste transportation method. This means that, people from Mikocheni where most of its residents are of medium or high class (income) manage to use such methods that demand money. For Mwananyamala ward where most of its residents earn below USD 1 per day opt for such methods that demand less or no money at all. These include the use of pushcarts, burning and/or individual members of household carrying bags of waste to the collection point. These findings concur with literatures by Angelo (2004) which postulate that, "...individual's income determine the way of acting on the environment...."

There were two main reasons for Mwananyamala residents to opt for such least cost transportation methods. First, the methods are cheaper or do not require money and secondly, most parts of Mwananyamala area are unplanned settlements; therefore, introducing transportation methods like open trucks or farm tractors as for Mikocheni, could mean to collect only waste from households that are situated near the main roads, leaving out interior parts of the ward unsaved. Figure 4.2 below is a comparison and overall methods used for transporting SW in the study area.

Frequencies and quality of the services: Despite that SW is a problem in both wards; the frequency and quality of the service provision was noted to be different. Mikocheni receive at least quality services and at a reasonable frequency. Majority of respondents (56.2\%) claimed to receive the services in undetermined frequencies and/ or no such service at all in their areas, (i.e. $38.2 \%$ and $18 \%$, respectively). More than three quarters of this percentage (53\%) were from Mwananyamala. From other respondents, $20.7 \%$ said that SW collection services are provided one to three times a month while for $18.4 \%$ the service was provided at least one to three times a week. It was only $4.6 \%$ who argued to receive waste collection services daily in their area; and they were all from Mikocheni. Figure 4 summarizes the average frequencies at which the service is provided in the study area. 
Similarly, results indicate that, the quality of services provision to the study area is unsatisfactory. More than half $(63.6 \%)$ of the total sampled population claimed the service to be poor; $14.3 \%$ from which claimed the services to be very poor. On other hand the service was satisfactory for $35 \%$ while it was said to be good only $1.4 \%$ whose service was good. There was no respondent who rated the service to be very good (Figure 4). These findings are consistent with earlier studies by Casmiri 2012 which show that SW is a problem in Dar es Salaam and Kinondoni Municipality in particular (Fgure 4).

Majority of respondents who claimed that the services are good or satisfactory in their area were from Mikocheni while those with poor and/or unsatisfactory services were from Mwananyamala. It should be remembered that Mwananyamala is occupied by majority of low income household, living in less than US\$ 1 per day while Mikocheni is home to many of the highincome suburbs. This is evidence telling that there is relationship between socio-economic characteristics of respondents and the quality of services provided at that particular area. With Pearson correlation analysis, the obtained value (72) indicates a strong positive correlation between location of respondents and other socio-economic characteristics of respondents and the quality of the services provided.
Alternatives for the Delayed Services: The study results reveal that SW collection services within the Municipality do not meet the existing demand. The situation is more serious in unplanned settlements like Mwananyamala ward where the roads networks do not allow vehicles to pass through the streets. Waste collection services are rarely provided and/or completely unavailable in some areas. Under such circumstance, each household has its own alternative and mechanism to cope with the situation. Such alternatives and mechanisms differ from low to high income earners. For low income class they use opening of landfills near homes, waiting until service providers collect, and take household generated waste to nearby disposal areas. Other related alternatives are like burning of the waste products. For the medium and higher income class, when it happens that services are not provided in time, their coping strategies are relatively different. On average, $90 \%$ of this group affords to hire private SW collectors and/ or send out their domestic servants to collect waste to the nearby collection points and stations. Based on this trend, the interpretation here is that, coping strategies used by individual household to the delayed or unavailable services depend much on income level. Those with low income use methods that require little or no money at all while their counterpart affords the use of money to meet this demand.

\section{Solid waste management challenges}

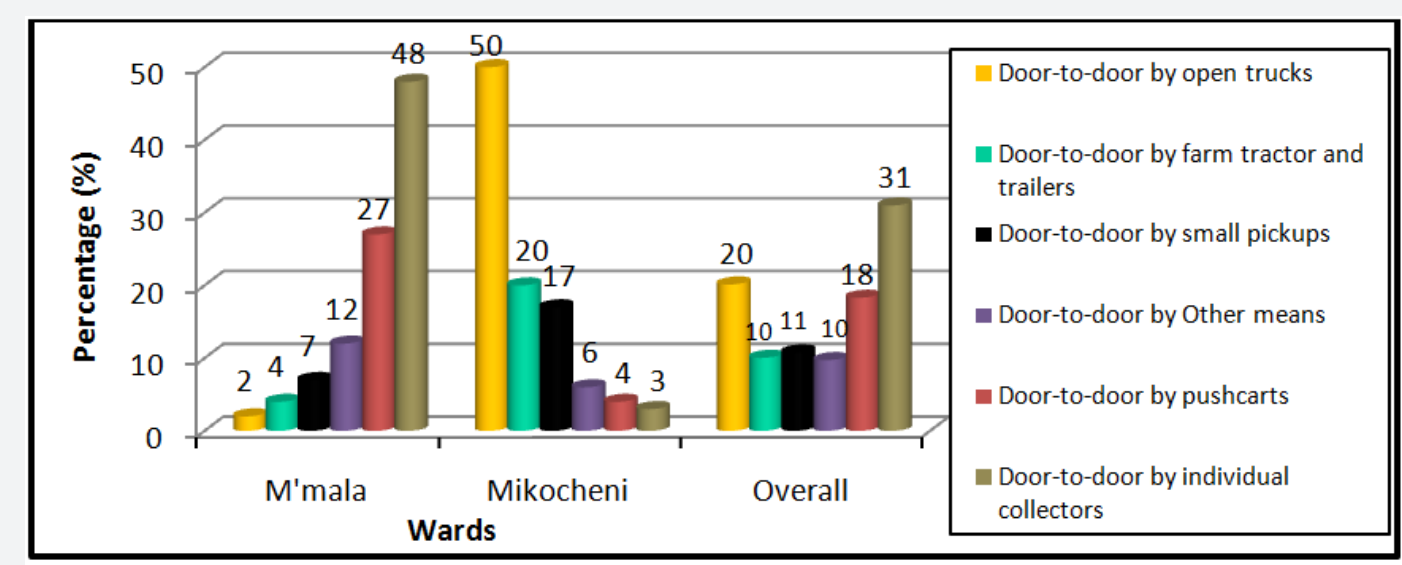

Figure 5: Solid waste transportation methods.

Source: Field data (2016).

Respondents claimed to have experienced numerous challenges in managing SW. Poor infrastructure and inadequate equipments and facilities were highlighted to be the leading challenges (Figure 5). Other challenges included lack of commitments among service providers, inadequate municipal communication capacities, low public awareness, ineffective legal framework, inadequate planning at the national level and other related challenges like bribes and corruption which result into engagement of unqualified collection contractors.

As shown in the (Figure 5), the intensity of the outlined challenges was noted to be different ward wise whereby factors like poor infrastructure seemed to be a serious challenge in Mwananyamala compared to Mikocheni. These challenges, support the earlier studies including that of Zurhrugg [16] which identified typical challenge of municipal SWM that are similar to the findings of this study. For the researcher, such similarity was of paramount importance in proposing EIs for SWM in local area; i.e. Tanzania and Kinondoni, in particular may use the same approach/es that have been used in other countries and had successful helped to solve or reduce intensity of SW problem in the respective areas (Figure 6). 


\section{International Journal of Environmental Sciences \& Natural Resources}

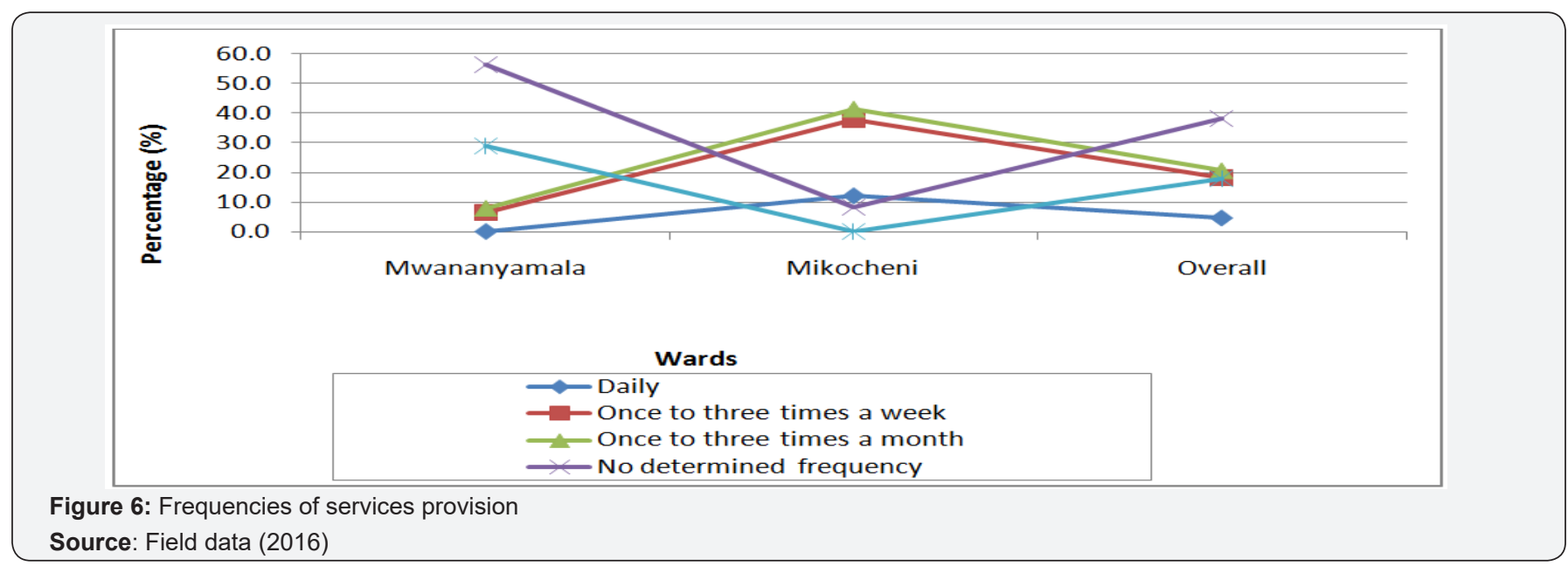

\section{The impacts of SW mismanagement}

Table 3: Impacts of mismanagement of SW.

\begin{tabular}{|c|c|c|c|}
\hline \multirow{2}{*}{ Impacts } & \multicolumn{2}{|c|}{ Percentage of households' responses (\%) } \\
\cline { 2 - 4 } & $\begin{array}{c}\text { Mananyamala ward (n= } \\
\mathbf{1 3 5}\end{array}$ & Mikocheni ward (n=82) & $\begin{array}{c}\text { Overall } \\
\text { (N=217) }\end{array}$ \\
\hline Waterborne and other related diseases & 25.2 & 7.3 & 18.4 \\
\hline Emergency of unauthorized dumping & 20.7 & 8.5 & 16.1 \\
\hline Putrid smell & 20.7 & 12.2 & 17.5 \\
\hline Blockage of sewage system & 20.0 & 34.1 & 25.3 \\
\hline Poor aesthetics & 8.9 & 15.9 & 11.5 \\
\hline Degradation of water and soil quality & 3.0 & 12.2 & 6.5 \\
\hline Other impacts & 1.5 & 9.8 & 4.6 \\
\hline Total & 100 & 100 & 100 \\
\hline
\end{tabular}

Source: Field data (2016)

Table 4: Most common diseases caused by poor management of SW (\%).

\begin{tabular}{|c|c|c|c|c|c|c|c|}
\hline \multirow[b]{2}{*}{ Diseases } & \multicolumn{7}{|c|}{ Yeas of diseases occurrences } \\
\hline & $\begin{array}{c}{ }^{2} \\
\text { Mikocheni } \\
a \\
(n=4124)\end{array}$ & $\begin{array}{c}12 \\
\text { M'nyamal } \\
b \\
(n=1976)\end{array}$ & $\begin{array}{c}\text { M'nyamal } \\
a \\
(n=4213)\end{array}$ & $\begin{array}{c}2013 \\
\text { Mikochen } \\
b \\
(n=2627)\end{array}$ & $\begin{array}{c}\text { M'nyamala } \\
a \\
(n=3435)\end{array}$ & $\begin{array}{c}2014 \\
\text { Mikochen } \\
\text { b } \\
(n=2550)\end{array}$ & $\begin{array}{c}\text { Total } \\
\text { (N=18925) }\end{array}$ \\
\hline $\begin{array}{c}\text { Malaria } \\
\text { Diarrhea } \\
\text { Lung diseases } \\
\text { Eye infections } \\
\text { Total }\end{array}$ & $\begin{array}{l}52.7 \\
12.9 \\
1.1 \\
0.8 \\
67.6\end{array}$ & $\begin{array}{l}24.2 \\
7.0 \\
0.4 \\
0.8 \\
32.4\end{array}$ & $\begin{array}{l}48.4 \\
11.6 \\
0.9 \\
0.7 \\
61.6\end{array}$ & $\begin{array}{l}29 \\
7.9 \\
0.5 \\
1.0 \\
38.4\end{array}$ & $\begin{array}{l}45.3 \\
1.0 \\
0.9 \\
57.4\end{array}$ & $\begin{array}{l}9.2 \\
0.7 \\
1.2 \\
42.6\end{array}$ & $\begin{array}{c}77.1 \\
19.5 \\
1.6 \\
1.8 \\
100\end{array}$ \\
\hline
\end{tabular}

Source: TMJ and Mwananyamala District Hospital (2016)

Due to poor management, waste is haphazardly dumped on informal areas like open spaces, in drains, manholes, along and across streets, and even along the main roads. Experience shows that, the impacts are almost the same from the given two wards though, with some differences in percentage compositions (Table 3). For instance, unauthorized dumping was a common feature in Mwananyamala ward while it was not so common in Mikocheni ward since majority of its residents manage to hire private collectors when it happen that services are delayed or unavailable. Another difference was on the impact of eruption of waterborne and other related diseases. In this case, while Cholera infections were reported in almost every rainy season at Mwananyamala ward, there were minor such cases at Mikocheni ward. Table 3 provides in summary the impacts of mismanagement of SW ward-wise. (Table 3) The study went further to seek medical evidence by interviewing medical personnel at Mwananyamala 
district hospital (MDH) for Kinondoni and TMJ medical centre in Mikocheni. They provided explanations and medical data on diseases related to mismanagement of SW. The data was based on medical records of patients who reported and got examined in hospital laboratories from 2012 to 2014 (Table 4). Since the researcher wanted to get medical information of Mikocheni and Mwananyamala residents while the hospital admit individuals from different areas, the interviewed personnel from the respective hospitals were requested together with medical data, to provide also the patient physical address. This was very important in assessing the impact of mismanagement of SW to health of residents at the study area only.

According to medical personnel, four types of diseases (together with other sources) were said to originate from unauthorized dumping and poor management of SW. These include diarrhea and malaria [3], lung diseases like coughs and eye infections [4] in varying proportions. On average, lung infections have been increasing over the years while Malaria was dramatically increasing in the first two years but in the last year probably due to several malaria campaigns, it was significantly decreased. For Diarrhoea cases, the infections more or less remained constant with an average fluctuating between $1.1 \%$ and $1.5 \%$ in from 2012 to 2014 . Except for eye diseases, in all other cases Mwananyamala was leading by having many reported cases of eruption of diseases. For the problem of eyes' diseases, Mikocheni was leading. This means that, there might be other source of eyes problems in the area other than fumes from the burning waste (Table 4).

\section{The use of Economic Instruments for SWM}

Despite the fact that there are some economic instruments (EIs) used in varying degree to manage SW in the study area, majority of respondents use them with little or without any knowledge if they were EIs. This was apparently marked by the number of respondents (about 90.3\%) who agreed to have been paying for SWM services but it was only $50.2 \%$ who were capable of identifying them as EIs. It was noted that, generally, there are few instruments such as applied fees, direct and service charges, and deposit-refund system which are used for the purpose in the study area and to the country at large. Other instruments like landfill tax, exercise duty on plastic bag, recycling credits and others have not been used and/or introduced in the study area.

Deposit and Refund System (DR-S): The deposit-refund system was discovered to be among the instruments used in the study area for SWM (Figure 7). However, it was not an adequate tool to cater for all kinds of waste. The instrument is used to some packing containers like soda bottles and cooking fats. For soda bottles, the consumer (buyer) pays extra money from the actual price (deposit) when purchasing a product. The extra payments are fully or partially reimbursed when the container (bottle) is returned to the dealer. In this way, it was very hard to find such products haphazardly dumped at any part of the area surveyed (Figure 7).

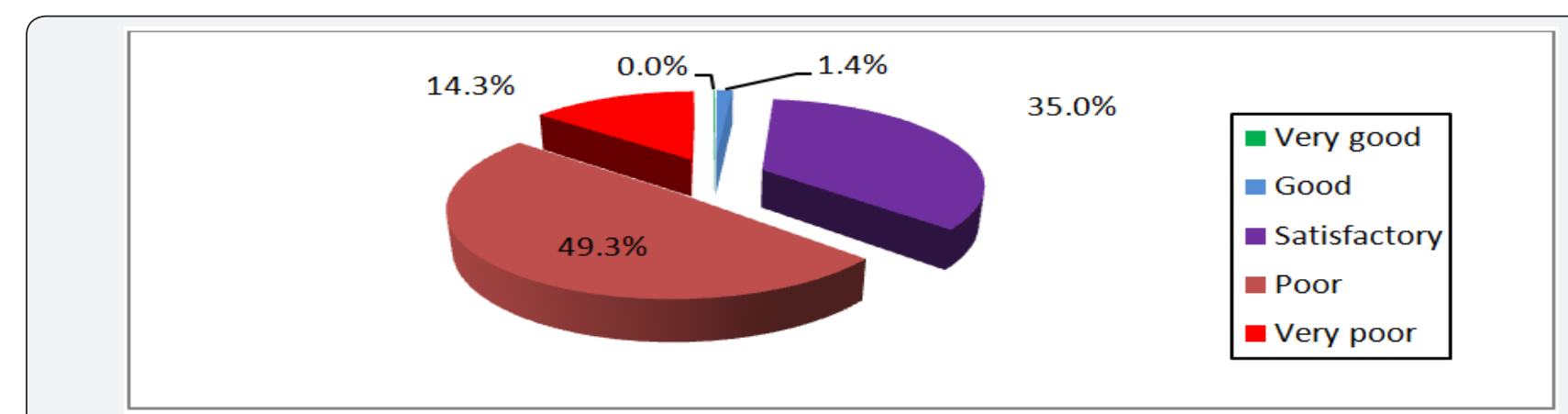

Figure 7: Responses on the quality of SW service provision.

Source: Field data (2016).

For cooking oils, the containers were sold at very low profit margins just to attract people to purchase the oils and the dealer sells the containers at higher prices to the actual manufacturers and to the collectors of the containers especially the metal ones. Information from the key informant shows that, in deciding the amount to be refunded, producers do not just decide from their own approximations. There are some conditions which are considered for deciding (calculating) the amount of refund. These include the cost of collecting and/ or buying new containers. Others (though not much considered) are the cost of cleaning the environment and the benefits of proper dumping.
The use of Fees for SWM: The fees for environmental quality and standards for waste disposal and management have been indicated under SEAR 2008. These include the required amount of application for registration and permit for disposing hazardous waste and chemical waste, and other related polluting permit like the permit for emission and discharge of waste. One of the anticipated results in this study was to see the area with residents who do not pay the required fees to be the one with poorer states of SW management than its corresponding part. To a great extent, the findings of this study coincided with this anticipated results. 


\section{International Journal of Environmental Sciences \& Natural Resources}

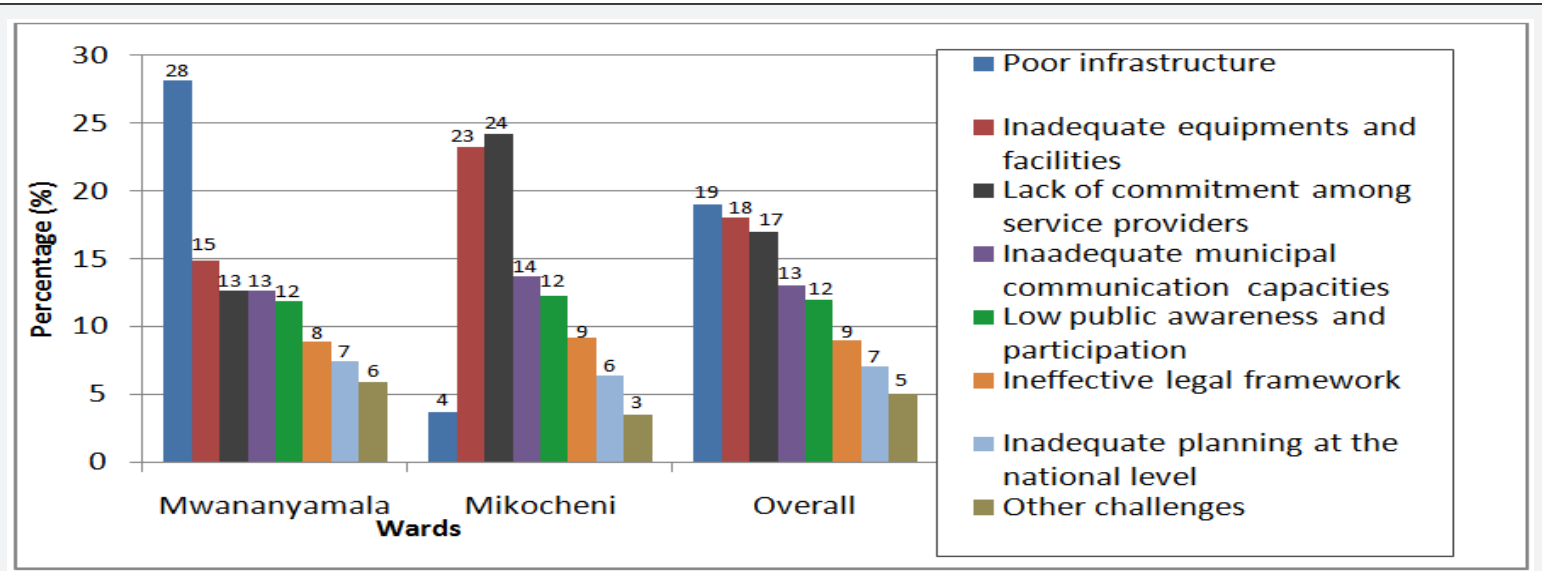

Figure 8: Percentage composition of SW management challenges. Source: Field data (2016).

As shown in (Figure 8) from $28 \%$ of the total respondents who thought that fee is the main instrument for SWM, only $16 \%$ were from Mwananyamala; the rest (84\%) were from Mikocheni. Mikocheni with such large percentage of fees compliances is the one with at least improved SW situation. This can be interpreted that, since SW problem seemed to be diminished in areas where residents and other waste producers comply with the prescribed fees, the instrument is therefore an important tool for SWM, i.e. with well-organized and monitored fees; SW problem may be reduced or completely eliminated in the area. It was further noted that, this overall (28\%) of fee compliance in the study area exceeded the overall national average which is only $18 \%$ SEAR, 2008. The reasons for such difference is probably due to education provided to people and some campaigns that insist people to pay fees and make use of other EIs in urban areas including Mikocheni and Mwanayamala.

The lesson that can be drawn here is that, in order to address the problem of SW through the use of EIs, the campaigns for applying these instruments must go hand in hand with mass education. Although the fees compliances in the study area exceeded the national average, there were still regulatory and management challenges which made the instrument less effective. When asked about the effectiveness of the instrument, only $2 \%$ of respondents commended it to be effective while
$41 \%$ commended it to be ineffective. For instance, despite the availability of regulatory and the prescribed fees, there were a number of unregistered small industries in both wards, some noted to operate within residential areas and even at homes. Astonishingly, it was noted that some local government leaders were aware of the situation but for unknown reasons, these small informal industries producing slippers (Yebo-yebo) and some other plastics materials, were yet operating. This indicates a serious weakness in implementing our policies, laws and regulations and therefore many small industries have been operating before they meet the prescribed conditions.

The use of Charges as an EI: Direct and service charges were noted to be the main economic instruments used in the study area to manage waste with an average use of $57 \%$ (Figure 9) Individual households pay for the service in different ways. For the place where collection service is rendered by the municipal authorities or by private companies (the whole of Mikocheni and some parts of Mwanayamala ward), they pay to services providers at every collection moment. This information went contrary with SW collection contractors (service providers). According to them, people do not paying for waste management services (WMS) and when they are forced to do so; they pay inadequately (Figure 9).

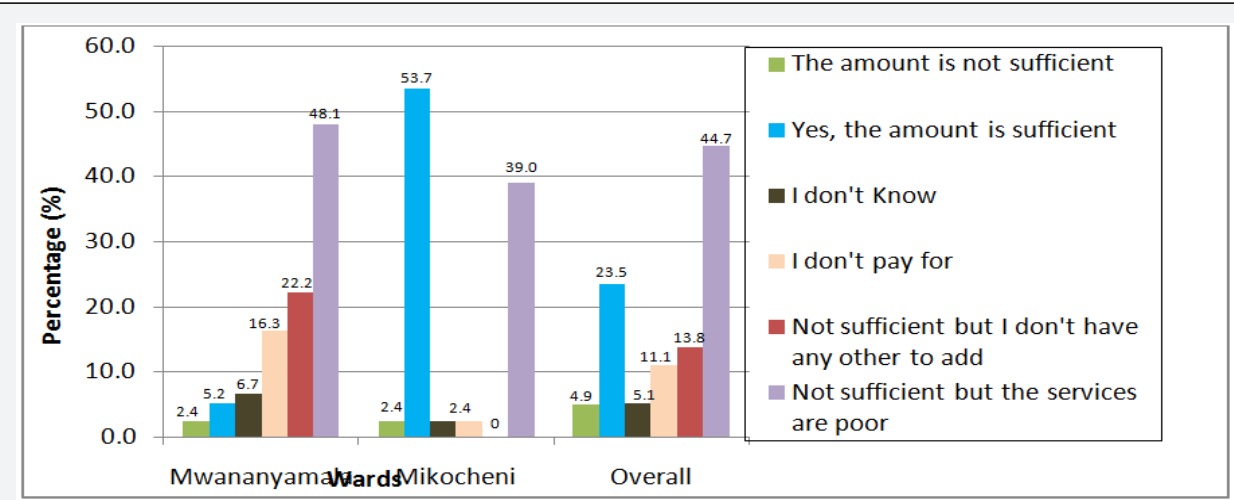

Figure 9: Respondents' views on the adequacy of the amount paid for SWM.

Source: Field data (2016). 
Such reluctances could be caused by having many servicedemands such as, inter alia, water, energy, transport, education and health care to pay for. With that long list of charged services, paying for waste collection was not of their priorities. Despite such information from collection contractors, the study found that, whether enough or not, people pay for waste management services. However, it was also noted that, people from one locality could pay the same amount of money, regardless of the quantity and nature of waste collected (flat rate charging system). The variations in the amount paid mainly depend on the location and status of the particular area as it could be judged by the raters (service providers).

For example, while in most part of served area at Mwananyamala the amount ranges from 200-500 TZS in each collection trip, it was 500- to above 2000 TZS at Mikocheni ward. The flat rate charging system was discovered to be one of the main hindrance factors for an effective application of EIs for SWM. By using descriptive statistical analysis, the study went further comparing income level of respondents (one of the socio-economic characteristics) with the amount that an individual household pays as SWM cost.

The results as presented in (Table 5). Show that there is strong evidence on the relationship between the given socioeconomic characteristics (income) and the amount that an individual household pays. (Table 5) Findings from the study show that from an overall of $14.7 \%$ of total respondents who were not paying for the services, $6.4 \%$ were from low income earners, while $5.0 \%$ were from middle class (Table 5). Only $0.9 \%$ equivalent to 2 respondents was from high income class. Likewise, from $28.0 \%$ of respondents paying below 1,000 T.shs per month, approximately $26.7 \%$ were all from low and middle income earners groups.

Table 5: A comparative analysis of Monthly income and amount paid for SWMS.

\begin{tabular}{|c|c|c|c|c|c|c|c|}
\hline \multirow{2}{*}{$\begin{array}{c}\text { Amount paid/ } \\
\text { status }\end{array}$} & \multicolumn{6}{|c|}{ Percent of respondents paying in respect to household monthly income (\%) } \\
\cline { 2 - 8 } & \multicolumn{2}{|c|}{ Low $^{1}(\mathrm{n}=62)$} & \multicolumn{2}{c|}{ Medium ${ }^{2}(\mathrm{n}=81)$} & \multicolumn{2}{c|}{ High $^{3}(\mathrm{n}=74)$} & Overall \\
\cline { 2 - 9 } Not Paying & 19.0 & 0.0 & 13.2 & 4.0 & 2.0 & 1.0 & 14.7 \\
\hline Below 1,000 & 42.5 & 0.3 & 32.4 & 5.9 & 1.0 & 2.0 & 28.0 \\
\hline $\mathbf{1 , 0 0 1 - 3 , 0 0 0}$ & 17.3 & 0.0 & 17.4 & 18.2 & 5.5 & 11.5 & 23.0 \\
\hline $\mathbf{3 , 0 0 1 - 5 , 0 0 0}$ & 4.3 & 0.3 & 2.1 & 17.2 & 3.4 & 28.2 & 17.5 \\
\hline Above 5,000 & 0.0 & 0.0 & 0.0 & 7.5 & 16.2 & 29.0 & 16.8 \\
\hline Overall & 28.3 & 0.3 & 20.5 & 16.8 & 9.6 & 24.5 & 100.0 \\
\hline
\end{tabular}

Source: Field data (2016)

Household earning below 300,000 Tsh per month

Household earning between 300,001-1,000,000 Tsh per month

Household earning above 1,000,000 per month

Table 6: A Correlation coefficient on Monthly household income and the amount paid for SWM services.

\begin{tabular}{|c|c|c|c|}
\hline & & Average monthly income & $\begin{array}{l}\text { Amount paid by Individual } \\
\text { household per month for } S W \\
\text { management }\end{array}$ \\
\hline \multirow{3}{*}{ Average monthly income } & Pearson Correlation & 1 & $.806^{* *}$ \\
\hline & Sig. (2-tailed) & & .000 \\
\hline & $\mathrm{N}$ & 217 & 217 \\
\hline \multirow{3}{*}{$\begin{array}{l}\text { Amount paid by Individual } \\
\text { household per month for SW } \\
\text { management }\end{array}$} & Pearson Correlation & $.806^{* *}$ & 1 \\
\hline & Sig. (2-tailed) & .000 & \\
\hline & $\mathrm{N}$ & 217 & 217 \\
\hline
\end{tabular}

${ }^{* \star}$ Correlation is significant at the 0.01 level (2-tailed).

Source: Field data (2016)

Only $1.3 \%$ was from high income class. Generally, individuals from low income class use alternative waste collection methods that demand little or no money at all while those with high income afford to pay for the service. Further analysis was made using SPSS software to conduct a correlation analysis to show how strong this relationship is. The Pearson correlation value (r-test) as presented in Table 6, counts .806. Based on the correlation coefficient interpretation guidelines by Rumsey, 2008, the interpretation for this value is that, 'there is a very strong evidence of a positive relationship between household's income and the amount of money paid for SW management services'.

This means that income level of an individual is among of the determinant factors for the amount that individual may pay 
for environmental management services. Therefore, if one wants to make people paying for the service he has to start by dealing with their living conditions. (Table 6) When asked whether or not the current paid amount is sufficient for the services, about half of the respondents (44.7\%) agreed with the idea that the amount paid is not sufficient to cater all necessary costs for the successful SWM but no way they could add any amount unless the services are improved. To the researcher, this was a good sign that if the services were improved, people might be willing to pay more for the services.

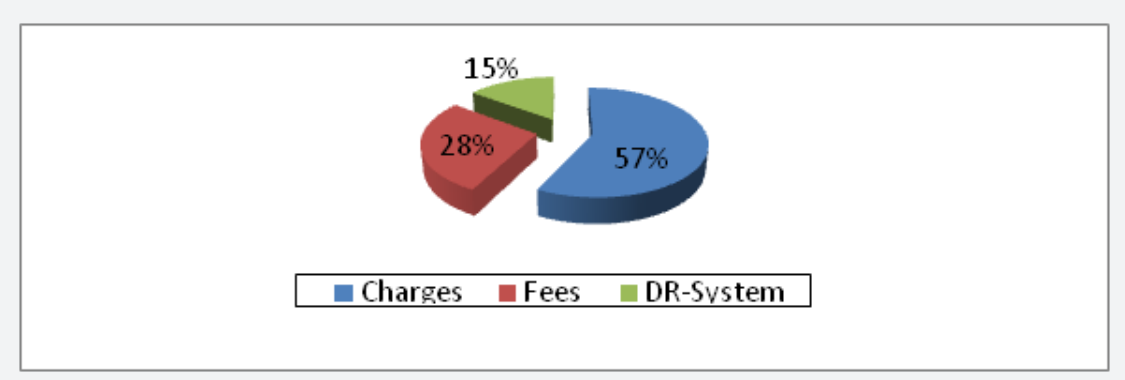

Figure 10: Percentage composition of in-use Els.

Source: Field data (2016).

The results on the adequacy of the amount paid are as indicated in (Figure 10) surprisingly, majority of respondents with such ideas (48.1\%) were from Mwananyamala. In this case, the findings went contrary to the study conducted by John (2009) on liquid waste management which postulated that, "individual with high income agrees that the amount paid is not sufficient so may be willing to add the prevailing paid amount than those of low income". For this study, whether they may add from the actual amount paid or not, majority of those with low incomes agreed to the notion that the prevailing amount paid is insufficient. This indicated a good sign for introducing the efficient economic instruments, i.e. with well-structured mechanisms; people may be willing to add more money for the service regardless of their income.
Generally, on average, more than half (57\%) of the total respondents who are aware of these EIs claim that, charges was the most used tool in their area compared to other instruments. One of the new generated knowledge was in this area. The study by Klarer [23] presented taxes as the main EIs used in Tanzania and Kinondoni [24-26] in particular. The limitation of this study was that, it focused only on large scale instruments like excise duty on plastic bags, VAT on petroleum, motor vehicle taxes, and excise duty on petroleum and fuel levy, while underestimating such instruments which could be applied at local level including wards. Focusing on this gap, this study discovered charges, fees and DR- system as the main EIs applied in the study area; however they were not well monitored (Table 7). If well organized, these instruments have a capability to solve SWM problems at local area like wards and even ten cells (Figure 10).

\section{Socio-Economic characteristics of respondents and WTP for SWM Services}

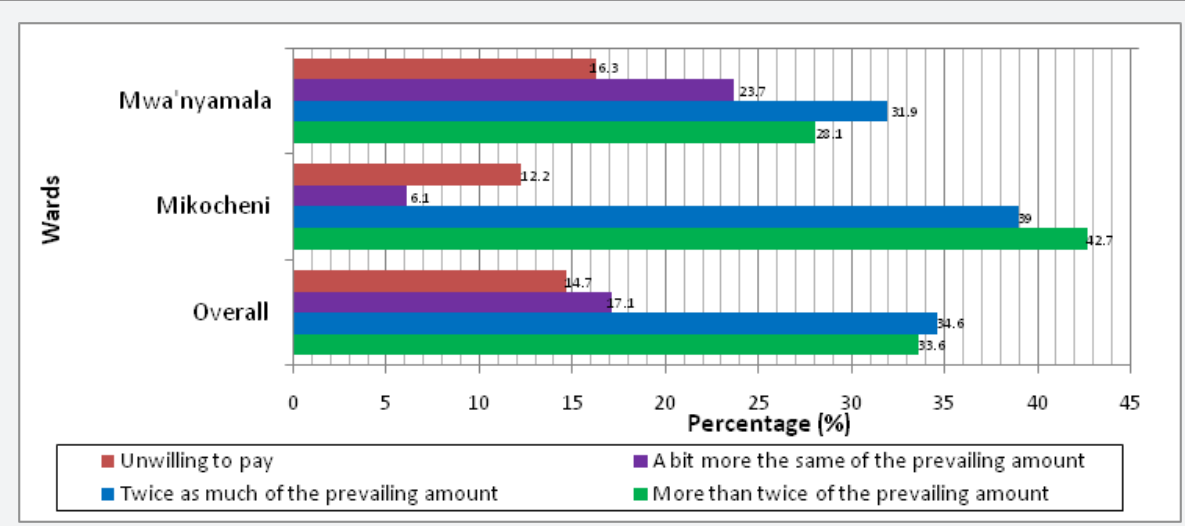

Figure 11: An amount that individual households are WTP in addition for SWMS.

Source: Field data (2016).

The study findings revealed that, majority of respondents (85.3\%) were willing to pay more (WTP) for solid waste management services (Figure 11). It was only $14.7 \%$ who were not willing to pay higher than the prevailing amount. However, such willingness was conditioned to the assurance and commitment from service providers to improve and provide adequate services. The amount that individual households would be willing to pay in additional from the prevailing amount so as to meet the actual collection cost varies significantly with different socio-economic setting of individual household. 
Respondents were provided with open-ended questions to provide explanation and results were as shown in Figure 11 below.

Except for the overall percent of unwillingness to pay $(14.7 \%)$, to a great extent, the variations on the actual amount that could be added were based on individual differences on socio-economic position. This emphasized the notion that there is a relationship between socio-economic characteristics of the population with the amount that respective population pays for environmental management initiatives. Although it was only $14.7 \%$ who indicated their unwillingness to pay for SWMS, the reasons provided seem to have more weight and wealth to work on.

The respondents highlighted different reasons for their unwillingness to pay. These include lack of money to pay or add from the prevailing amount, some consider paying for SWMS to be not their role but of the government and another group pointed out that they did not believe that any addition of money will help to solve the problem rather they were of the views that management of SW will take place even without their extra contribution (Figure 12). This suggests that poverty and lack of trust to the government in overcoming SW problem are their major issues. Unless those issues are addressed, SW may remain a problem for many years to come. The government needs to enforce its laws with regard to waste management (Figure 12).

Factors determining the willingness to pay more for SWMS: Willingness to pay (WTP), as previously described was measured using different social and economic aspects. The objective here was to find out if there is any relationship between socio-economic characteristics of respondents and their willingness to pay more for SWM services. Several tests were carried out to determine how the highlighted socio-economic characteristics affect individual's WTP. As a dependent variable, WTP was analysed against several independent variables like gender, education level, and type of employments (occupation), age, income level, and household size of respondents. When running the tests, some SPSS contents like Cross-tabulation, Chisquare (X2) and correlation analysis were used and presented as follows. Initially, the researcher had two assumptions, the null and alternative hypothesis; condition for running Chisquare test. (Table 7) From (Table 7) (II) above, the value for Chi-Square (X2) is 2.577 , the critical value (minimum expected count) is 11.94 and the degree of freedom (df) is 1.

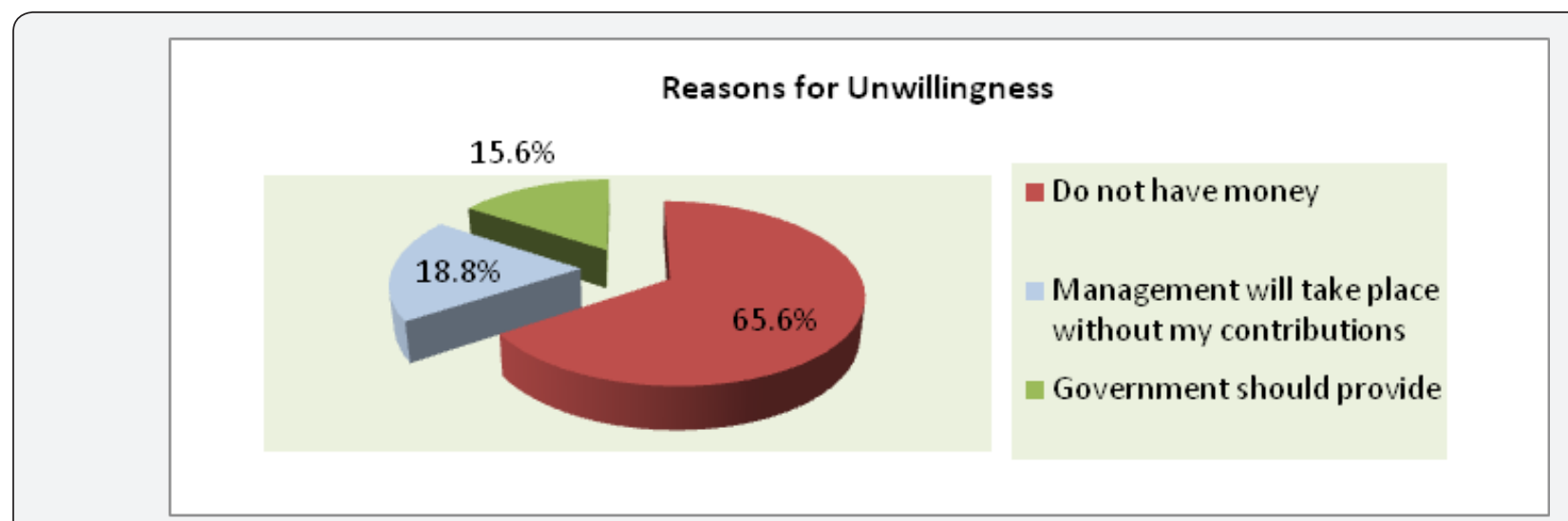

Figure 12: Reasons for unwillingness to pay more for SWMS.

Source: Field data (2016).

Table 7: Crosstabs and Chi- Square results on respondents' WTP against some socio-economic characteristics

\begin{tabular}{|c|c|c|c|c|c|}
\hline \multicolumn{6}{|c|}{ I: Crosstab Results } \\
\hline & & \multicolumn{2}{|c|}{ Gender of respondents } & \multicolumn{2}{|c|}{ Overall (\%) } \\
\hline & & Male $(n=81)$ & Female $(n=136)$ & & \\
\hline \multirow{2}{*}{$\begin{array}{l}\text { Respondents' WTP for } \\
\text { SWM if the services } \\
\text { are improved }\end{array}$} & No $(\mathrm{n}=32)$ & $21.0 \%$ & $11.0 \%$ & \multicolumn{2}{|c|}{14.7} \\
\hline & Yes $(n=185)$ & $79.0 \%$ & $89.0 \%$ & \multicolumn{2}{|c|}{85.3} \\
\hline \multicolumn{6}{|c|}{ II: Chi-Square Tests } \\
\hline & Value & $\mathrm{df}$ & Asymp. Sig. (2-sided) & Exact Sig. (2-sided) & Exact Sig. (1-sided) \\
\hline
\end{tabular}




\begin{tabular}{|c|c|c|c|c|c|}
\hline Pearson Chi-Square & & & .108 & \\
Continuity correlation & $2.577 \mathrm{a}$ & 1 & .159 & .117 \\
b & 1.981 & 1 & .113 & .109 \\
Likelihood test & 2.508 & 1 & & \\
Fisher's Exact Test & 2.565 & 1 & & \\
Linear-by-Linear & & & & \\
Association & 217 & & & \\
\hline \multicolumn{2}{|c|}{ N of valid Cases } &
\end{tabular}

a. 0 cells $(0.0 \%)$ have expected count less than 5 . The minimum expected count is 11.94

b. Computed only for a $2 \times 2$ table

Source: Field data (2016)

Based on the given two conditions and the calculated value for X2, df and the critical value, Alternative hypothesis was rejected and Null hypothesis has to be retained (ref. the conditions under sec data analysis techniques).

In other words: Since X2(2.577) < Critical value (11.94); assumption $\mathrm{X}$ was rejected and $\mathrm{Y}$ was retained; and since $\mathrm{df}$ (1)>.05; Assumption Y was Retained or null hypothesis was not rejected. That is to say, there is no direct relationship between gender and WTP for SWM. The same analysis was conducted for education level and the type of employment of respondents against willingness to pay and showed similar results. Regarding correlation analysis ' $r$ ' the intension was to measure the significance of individual's WTP by showing the relationship between variables and the strengths of relationships. Once again, the WTP was as dependent variable was measured against age and household size of respondents as independent variables. The obtained results are as presented in (Table 8) below.

By using the correlation coefficient interpretation guide, the researcher was able to interpret the obtained value above as follows (Table 9).

Table 8: Correlation Coefficient of Respondents' WTP for SWMS.

\begin{tabular}{|c|c|c|c|}
\hline \multicolumn{2}{|c|}{ Dependent variable } & Independent variable (r-value) \\
\cline { 2 - 3 } & & & Household size \\
\hline & & .001 & -178 \\
$\begin{array}{c}\text { Respondents' WP for SWMS if } \\
\text { the service improved }\end{array}$ & Pearson correlation & .988 & .009 \\
& Sig. (2-tailed) & 217 & 217 \\
\end{tabular}

Source: Field data (2016)

Table 9: Interpretation for correlation coefficient of Respondents' WTP for SWM.

\begin{tabular}{|c|c|c|}
\hline Dependent variable $\rightarrow$ & \multicolumn{2}{|c|}{ Respondents' WTP for SWMS if the services are improved } \\
\hline Independent variables $\downarrow$ & Obtained Pearson correlation value & Interpretation \\
\hline Age & .001 & $\begin{array}{c}\text { There is very weak positive correlation } \\
\text { between age of respondents and their } \\
\text { willingness to pay for SWMS }\end{array}$ \\
\hline Household size & -178 & $\begin{array}{c}\text { There is weak negative correlation between } \\
\text { Household size and the willingness to pay for } \\
\text { SWMS }\end{array}$ \\
\hline $\mathrm{N}$ & \multicolumn{2}{|c|}{217} \\
\hline
\end{tabular}

Source: Field data (2016)

Generally, all results from Chi-square test and correlation analysis revel that majority of respondents were willing to pay for SWMS. However, it was discovered that their socio-economic characteristics like age, income, marital status, household size, education etc. were only the determinant factors for the actual amount paid but did not affect their willingness to pay. 
The willingness to pay is only determined by the assurance from the concerned authorities and service providers that, the services will be improved and adequately provided. This means that for sustainable SW management, the service from service providers and other relevant authorities must be timely and adequately provided to motivate community willingness to pay and participate in those initiatives. The finding of this study adds some knowledge which was the gap from several reviewed literatures which proposed command and control (CACs) regulations to be the main technique to get rid of SW problem. From the results above, this study advocates for collaboration of both EIs and CACs for sustainable SWM [28-30]

The Impact of applying EIs on SWM: It was noted that, EIs application has potentially helped solid waste and general environmental management. If well organized, they bring about both direct and indirect positive impacts to the community and the government at large. They have for instance noted to have had provided formal and informal employments, been a source of government revenue and reduce SW production rate by encouraging 3R (Reduce, re-use and recycle) in the study area. They have also helped to reduce SWM cost and encouraged public and private partnership. However, the instruments have also noted to face a number of challenges (hindrance factors), which make their implementation insignificance. This (among other factors) are contributed by the fact that, the prevailing management strategies are still inefficient, unreliable and unequally provided. Flat rate charging system, inappropriate knowledge regarding the instruments and lack of coordination and collaboration among stakeholders are some of these management challenges. Again, lack of necessary capacity for monitoring and poor management initiatives are also contribute to the insignificance of these instrument [31-34].

\section{Conclusion}

As the information obtained from the field shows, solid waste and general environmental sanitary is a problem in Kinondoni Municipality specifically at the study area and is of more concern in squatter and unplanned settlements. Together with other interventions for SW monitoring like command and control regulations (CACs), few economic instruments (EIs) used have not been of much help to get rid of the problem since a number of challenges face their effective applications. There are also numbers of EIs which have not been used in the country for environmental management but their applications in other countries indicate positive signs toward sustainable SWM. The important promising status was that, people are ready to use these EIs and are willing to pay for the service, irrespective of their socio-economic characteristics, only if they are assured of adequate services.

\section{Area for further Research}

There is a room for further study on application of modern EIs and approaches that use both CACs and EIs by using large sample and put much emphasis on large cities in the country which have large waste generation rates. The study should assess more factors governing individuals' willingness to pay and use such instruments for sustainable environment and solid waste management in particular. Such study may assist in drawing inferences for the region, and use the proposed instruments at large scale for sustainable solid waste management.

\section{References}

1. Omololu 00, Lawal SA (2012) Population growth and Waste Management in an African City, University of Ibadan, Ibadan, Nigeria.

2. Ntakamulenga R (2012) The status of solid waste management in Tanzania: A paper presented during the coastal East Africa solid waste workshop held in Flic en Flac, Mauritius pp. 10-13.

3. Robert B (2012) Municipal solid waste management in Dar es Salaam: Draft baseline analysis, The World Bank, USA.

4. Buenrostro O (2011) Urban Solid Waste generation and disposal in Mexico. Journal of Environment Development 29(10)

5. Williams PT (2005) Waste treatment and Disposal, Second edition, Jeam Wiley and Sons Ltd, Chichester.

6. Angelo B (2004) Lands of the Poor: Local Environmental Governance and the Decentralized Management of Natural resources, UNCDF, USA.

7. USEPA (2011) Wastes Resource Conservation of Common Wastes and Organic Materials

8. Philips L (2001) Environmental impacts related to landfill practices in cities, UDSM, Tanzania

9. UNES (2014) World Urbanization Prospects: Highlights, Department of Economics and Social Affairs, New York,USA.

10. Abduli MA (1996) Industrial waste Management in Teheran. Journal of Environmental International 22 (3)

11. EPA (2012) Wastes - Non-Hazardous Waste - Industrial Waste, US Environmental protection agency (EPA).

12. Lyeme A (2011) Optimization of Municipal solid waste Management System, (Un-published), University of Dar es Salaam, Tanzania.

13. Halla F, Majani B (1999b) Innovative Ways for Solid Waste Management in Dar es Salaam: Towards Stakeholder Partnerships. Habitat International 23(3): 339-350.

14.Zurbrugg C (2003) Improving Municipal Solid Waste Management, Department of Water and Sanitation in Developing Countries (SANDEC), Swiss Federal Institute for Environmental Science and Technology (EAWAG), 8600, Duebendorf, Europe.

15. UNEP (1992) Capacity development for comprehensive urban solid waste management.

16. Gervais C (2002) An Overview of the European Waste and Resources Management Policy, Forum for the Future London.

17. Powell J, Craighill A (2000) Waste management: Environmental Science for Environmental Management, Second Edition Pearson education Ltd pp. 469-484.

18. Godfrey, Nahman (2011) Economic instruments for solid waste management in South Africa: Opportunities and constraints, Council for Scientific and Industrial Research, South Africa.

19. Klarer J (2011) "Improving Environment and Economy: The Potential of Economic Incentives for Environmental Improvements and Sustainable Development in Countries with Economies in Transition", the Regional Environmental Center of Central and Eastern Europe Szentendre Hungary 
20. Turner RK (2004) Environmental economics: An Elementary introduction, Pearson Education Ltd. Harlow.

21. Cointreau S (2003) The Application of Economic Instruments in Water and Solid Waste Management: Global Review of Economic Instruments for Solid Waste Management in Latin America, Inter-American Development Bank, Regional Policy Dialogue, USA.

22. Rasht (2009) “Economic Instruments and the Environment: Selected Legal Issues, West Coast Environmental Law Research Foundation and Environment Canada", Canada, USA.

23. Arthur D, Eduljee G (2001) "Solid Waste Management" In Harrison, R(Ed), pollution: Cause, Effect and control, Fourth edition, The Royal society of Chemistry, Cambridge.

24. DEFRA (2005) Guidance on applying the waste hierarchy, Department for Environment food and rural affairs, UK.

25. World bank (2013) What a Waste: A Global Review of Solid Waste Management, World Bank report, Washington, USA.

26. KMC (2014) Socio-economic description of the Districts: Kinondoni Municipality.
27. UN-Habitat (2010). Solid waste management in the world's cities: water and sanitation in the world's cities.

28. Cointreau S (1994) Private Sector Participation in Municipality Solid Waste Services in developing countries. The formal sector urban management programme Discussion (1): 13.

29. Cooper T (2001) Waste: Striving for a More Sustainable Future, Local EnvironmentEDB Inc,UK 6(2):

30. NBS (2012) The Government Population and Housing census.

31. Mutta D (2010) Nairobi convention: Management and development of the Marine and coastal Environment of the western Indian ocean, UNEP- DEPI Africa.

32. Solomon AO (2011) The role of households in solid waste management in East Africa capital cities: EPS.

33. UN (2009) "New Tax Slashes Irish Plastic Bag Consumption" Irish Environment Ministry

34. Webgroup (2008) "Type of solid waste”.

This work is licensed under Creative Commons Attribution 4.0 Licens

DOI: 10.19080/IJESNR.2017.04.555644

\section{Your next submission with Juniper Publishers will reach you the below assets}

- Quality Editorial service

- Swift Peer Review

- Reprints availability

- E-prints Service

- Manuscript Podcast for convenient understanding

- Global attainment for your research

- Manuscript accessibility in different formats ( Pdf, E-pub, Full Text, Audio)

- Unceasing customer service

Track the below URL for one-step submission https://juniperpublishers.com/online-submission.php 